\title{
INTERCEPTOR DE AREIA E RESÍDUOS URBANOS EM BOCAS DE LOBO
}

Helves Vieira Gomes - helves.vieiragomes@yahoo.com.br

Centro Universitário de Belo Horizonte - Unibh

Ana Carolina Neves Petes - anacarol2213@gmail.com

Centro Universitário de Belo Horizonte - Unibh

Ana Vitória Moreira Martins - anavitoriamm@yahoo.com.br

Centro Universitário de Belo Horizonte - Unibh

Angel dos Santos Craveiro - angelcrav@ hotmail.com

Centro Universitário de Belo Horizonte - Unibh

Amanda Maciel Pontes - amandamacielp@yahoo.com.br

Centro Universitário de Belo Horizonte - Unibh

Francielle Machado de Oliveira - francielle_kk@hotmail.com

Centro Universitário de Belo Horizonte - Unibh

Jamile Ribeiro - jamileribeiro.com@ hotmail.com

Centro Universitário de Belo Horizonte - Unibh

Ludmila Thamaris de Oliveira - ludthamaris@ gmail.com

Centro Universitário de Belo Horizonte - Unibh 


\section{RESUMO}

Este estudo visa a construção de um protótipo de interceptor de areia e outros resíduos a ser instalado dentro das bocas de lobo. Este interceptor terá uma entrada de água com dissipadores de energia; uma câmara com o fundo e parte da frente permeável, e o restante da parte da frente e a parte superior fechadas com grelha. Esta é a câmara de retenção da areia e demais resíduos. Será dotada de abertura de escape na parte superior para vazão da água em caso de obstrução da câmara de retenção por excesso de resíduos sólidos. A parte superior do interceptor (grade) será móvel para facilitar a limpeza da câmara, que poderá ser realizada manualmente, mas preferencialmente por caminhão dotado com sistema de sucção, para otimizar o processo. As dimensões atuais das bocas de lobo não serão modificadas, devendo o interceptor ser construído conforme suas medidas. Nos novos modelos de boca de lobo, que já são padronizados, padroniza-se também o interceptor. Este poderá ser construído de metal ou argamassa (pré-fabricado).

\section{INTRODUÇÃO}

As cidades que possuem grandes áreas impermeabilizadas enfrentam sérios problemas de inundações durante os períodos chuvosos. Além de drenagens insuficientes, soma-se ao problema a ocupação irregular do solo e resíduos sólidos obstruindo o sistema público de drenagem (UFRRJ, 2016).

Na cidade de Belo Horizonte, Minas Gerais, como exemplo, a empresa responsável pela limpeza urbana, SLU - Serviço de Limpeza Urbana, entre os anos de 2009 a 2014 retirou em média 4.334,57 toneladas de resíduos das bocas de lobo por ano (PORTALPBH, 2016).

Este valor retirado representa apenas os resíduos que ficaram retidos ou presos por obstrução nas bocas de lobo, e não contempla os resíduos que foram carreados para os corpos hídricos.

Os modelos atuais de bocas de lobo não são construídos para separar e ou reter materiais sólidos carreados pelas chuvas ou águas servidas, de modo que estes materiais causam obstruções das redes coletoras pluviais, lançamento de resíduos nos corpos hídricos e assoreamento.

A capacidade de engolimento de projeto de uma boca de lobo é fixada em 40 a $60 \mathrm{~L} / \mathrm{s}$ (FAUUSP, 2015).

A drenagem de águas pluviais faz parte do saneamento urbano, que é um conjunto de serviços de infraestrutura, como abastecimento de água, esgotamento sanitário, limpeza 
e drenagem urbana e manejo de resíduos sólidos e águas pluviais, que toda cidade necessita ter para a manutenção da saúde de sua população (TRATABRASIL, 2013).

Ainda conforme estudos do Instituto Trata Brasil, 2013, o saneamento básico está relacionado com o desenvolvimento de um país, pois reflete diretamente na saúde da população, melhoria da qualidade de vida, redução da mortalidade infantil, valorização dos imóveis e preservação dos recursos hídricos com consequente redução dos gastos no tratamento de água para abastecimento público. No Brasil, por exemplo, centenas de milhares de crianças de 0 a 10 anos são internadas anualmente, e 65\% dos diagnósticos são males oriundos da inexistência de saneamento básico.

A drenagem urbana, o manejo de resíduos sólidos e águas pluviais está diretamente relacionado à estrutura chamada Boca de lobo.

Boca de lobo é uma estrutura hidráulica para captação das águas pluviais e servidas, escoadas pelas sarjetas. Em geral, situam-se sob o passeio ou sob a sarjeta (BRASIL, 2012). Estas estruturas recebem todo o resíduo carreado pela água escoada, causando obstrução, necessitando de limpeza e manutenções periódicas.

Sarjeta e o sarjetão são canais longitudinais situados entre a pista de rolamento e a calçada, destinado a conduzir a água até as bocas de lobo (DER, 2006).

O objetivo deste estudo é construir um protótipo de Boca de Lobo que faça a separação mecânica dos resíduos sólidos como material plástico, folhas de árvores e principalmente areia, carreados pela água que escoa pela sarjeta com o objetivo de reduzir o lançamento destes nas redes pluviais e corpos hídricos.

\section{METODOLOGIA}

O modelo desenhado para a criação do protótipo do Interceptor de resíduos foi concebido através de discussões e brainstorming nas reuniões da equipe de trabalho. Baseou-se nos princípios básicos de filtragem, bem como a retenção de resíduos por meio de grelhas (MORGADO, 2014).

O Interceptor será parte integrante da Boca de lobo, instalado em seu interior, dotado de uma câmara de recepção e retenção da areia e demais resíduos urbanos. Esta câmara terá o fundo e parte da frente recoberta por material filtrante, e o restante da frente e parte superior será constituída de tela com malha de $3 \mathrm{~cm}$. A parte superior será removível para acesso ao interior da câmara e manutenção. O filtro será removível, fixo por uma moldura de concreto, para eventuais substituições em caso de saturação por areia.

A parte superior do Interceptor, acima da tela removível, será a passagem de emergência. Se a câmara for obstruída por excesso de resíduos durante alguma precipitação pluvial, a 
água passará direto para a saída da Boca de lobo, e o resíduo ficará retido na câmara. Os dissipadores de energia na entrada da câmara do Interceptor impedirão que a água de entrada caia direto sobre o filtro forçando a passagem de areia, além de reter os resíduos maiores em caso de obstrução.

As dimensões propostas estão na figura abaixo:

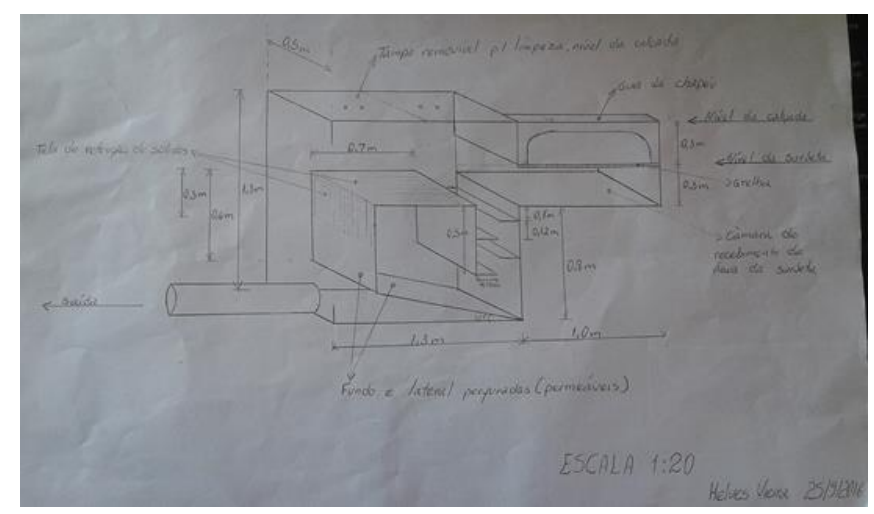

Figura 1 - Esboço do protótipo com as dimensões

Fonte - Arquivo pessoal, 2016.

O protótipo deste Interceptor de areia e resíduos urbanos em Bocas de Lobo foi construído, em sua maior parte com materiais reciclados, adquiridos em comércio de materiais usados, agregando sustentabilidade ao protótipo. Foram utilizados os seguintes materiais reciclados: 05 chapas de aço $(1.22 \times 0.40 \times 0.002 \mathrm{~m}), 01$ grade de carrinho de feira, 01 lata vazia de leite em pó. Materiais não reciclados: $01 \mathrm{~m}^{2}$ de tela de feltro, $01 \mathrm{~m}^{2} \mathrm{de}$ vidro $06 \mathrm{~mm}, 02$ latas de zarcão, 03 tubos de silicone, 02 dobradiças de $0.02 \mathrm{~m}, 05$ metros de fita adesiva asfáltica.

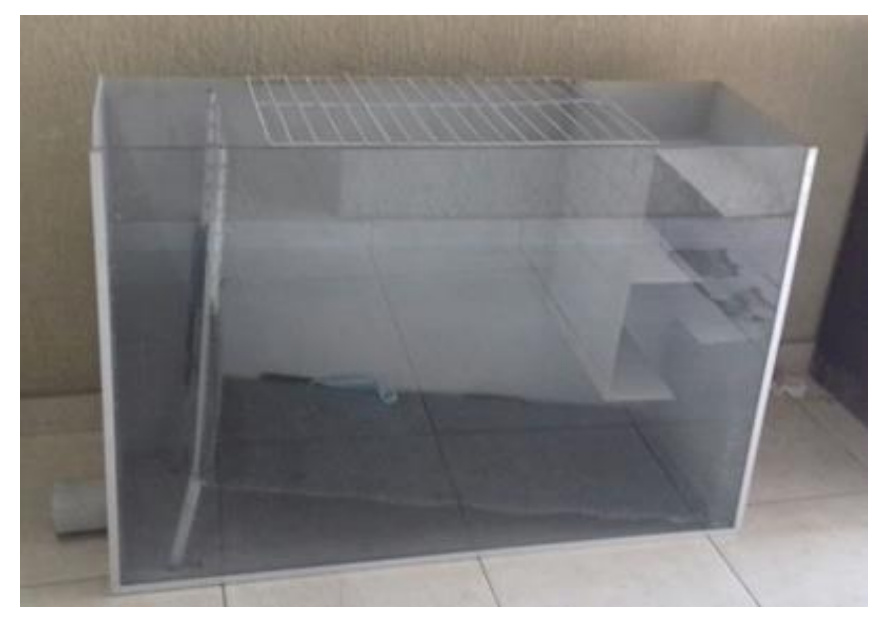

Figura 2 - Protótipo do interceptor de areia e resíduos urbanos em bocas de lobo Fonte - Arquivo pessoal, 2016. 
Vale ressaltar que as medidas atualmente utilizadas para as bocas de lobo em uso serão mantidas, embora não sejam padronizadas por falta de regulamentação (TOMAZ, 2012). O protótipo desta pesquisa será uma parte integrante das bocas de lobo, sendo instalado na parte interna da caixa de captação sob a calçada ou via pública, de modo que suas dimensões poderão variar conforme o espaço interno destas caixas, desde que nas proporções devidas.

O Interceptor deverá ser construído de concreto pré-moldado, como a maioria das novas bocas de lobo, para que seja padronizado, o que é o recomendado. Mas poderá também ser adaptado para os modelos mais antigos conforme suas dimensões.

A adaptação necessária para o novo modelo será a existência de uma tampa removível sobre a caixa de captação para a limpeza da câmara de retenção de sólidos do interceptor. Esta limpeza poderá ser manual, mas recomenda-se a limpeza pelo caminhão dotado de sistema de sucção de resíduos sólidos, para redução de custos e otimização do sistema de drenagem, visto que em períodos de precipitações pluviais a limpeza deverá ocorrer com maior frequência, devendo ocorrer vistorias das bocas de lobo situadas em áreas com históricos de alagamentos.

Na cidade de Belo Horizonte, a SLU mapeou locais de monitoramento estratégico, devido a alagamentos, mapeando cerca de 5.675 bocas de lobo. Estas representam 9\% do total, visto que a cidade possui 60 mil bocas de lobo. Além da atenção redobrada nestes locais, a prefeitura e SLU realizam parcerias e mobilizações sociais (PORTALBH, 2016).

Quanto à manutenção do filtro de tela de feltro, deverão ser feitos novos testes para determinação de saturação de areia do material, para determinar os períodos de trocas do filtro, quando ele passar a apresentar elevado tempo de filtração e retenção de água. Este filtro também será removível, sendo fixado por uma cantoneira de concreto no formato de moldura, apenas encaixada no fundo, sobre a tela de feltro.

Para realização dos testes do protótipo do interceptor, foi construída uma bancada de madeira revestida com material plástico de embalagens de bobinas de aço, para simular a sarjeta, com uma inclinação de $10^{\circ}$.

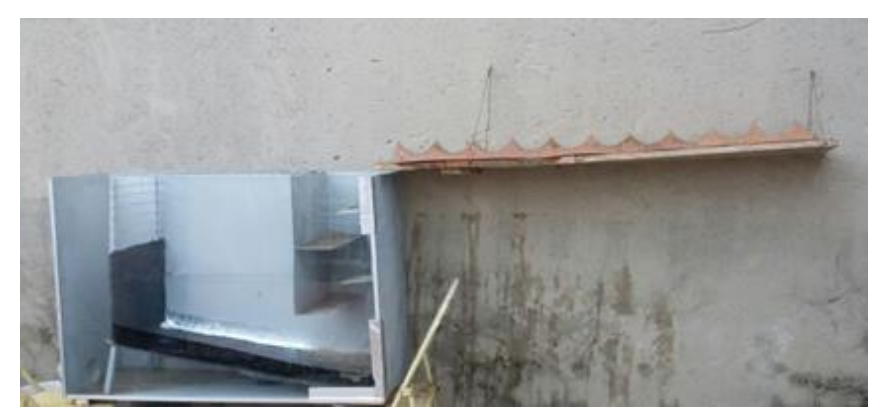


Figura 3 - Bancada para testes

Fonte - Arquivo pessoal, 2016.

Foram coletados 2 litros da água passada pelo filtro para decantação e mensuração da granulometria do particulado em suspensão. Este volume de água ficou cerca de 15 dias em recipiente aberto para evaporação e concluído o processo de secagem em estufa, por 24 horas e a $105^{\circ} \mathrm{C}$. Após a secagem o particulado foi medido em peneira granulométrica no laboratório de materiais do Campus Estoril do Instituto de Engenharia e Tecnologia IET UNIBH (Centro Universitário de Belo Horizonte).

\section{RESULTADOS E DISCUSSÕES}

Para o primeiro teste, com apenas areia e água, foi utilizado água tratada, 20 litros aproximadamente, e $3 \mathrm{~kg}$ de areia lavada industrial grossa e fina, misturadas. Para o segundo teste, com resíduos sólidos, utilizou-se água cinza, de máquina de lavar, aproximadamente 60 litros.

No primeiro teste, com apenas água e areia, foi pesada a mistura dos dois, totalizando $17,7 \mathrm{~kg}$. Após a filtragem pelo protótipo do interceptor, a água foi coletada e pesada novamente, 13,2 kg. Subtraindo a água perdida no processo, cerca de 2 litros, a retenção da areia foi maior que $90 \%$, visto que a areia utilizada foi pesada antes separadamente, $3,0 \mathrm{~kg}$.

Foi comparada a turbidez da água com areia antes e depois, apresentando significativa diferença, atestando a eficiência na retenção da areia, que visualmente era detectada apenas devido à turbidez, por estar presente em granulometria muito pequena.

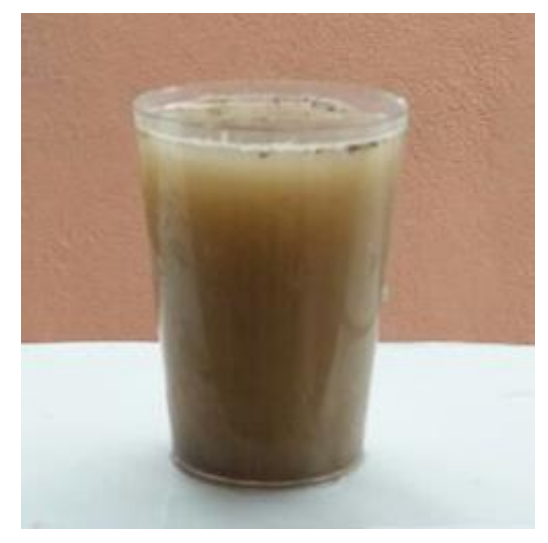

(A)

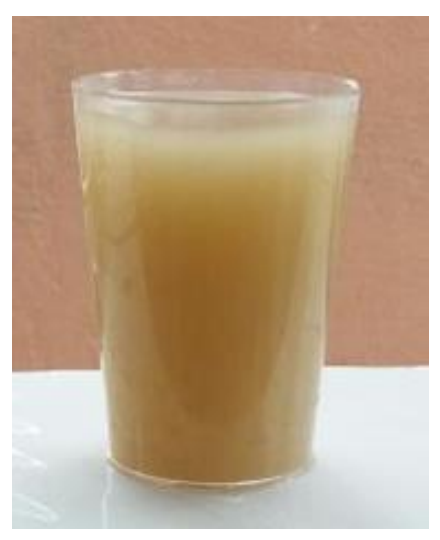

(B)

Figura 4 - Água com areia antes de passar pelo Interceptor (A). Água com areia após passar pelo Interceptor (B).

Fonte - Arquivo pessoal, 2016. 
A granulometria da areia que passou pelo filtro foi menor que $75 \mu \mathrm{m}$, medida na peneira número 200, menor medida disponível no laboratório de ensaios utilizado. Esta peneira ainda não conseguiu reter o particulado, passando mais de $90 \%$ do mesmo, indicando esta medida para a areia passante pelo filtro do interceptor.

Para o segundo teste, além da água cinza, foram utilizados os seguintes resíduos: embalagem de 01L de desinfetante, sacolas plásticas, pedaços de papelão, embalagem de sabonete, prendedor de roupas, folhas de árvores, pelos de cães, pedaços de isopor.

Para o bombeamento da água na bancada (sarjeta), foi utilizada uma máquina de lavar, marca Brastemp $11 \mathrm{~kg}$, com uma vazão média de $0,4 \mathrm{~L} / \mathrm{s}$. Para aumentar a vazão para o carreamento completo dos resíduos, foram lançados 36 litros de água manualmente, numa vazão média de $3 \mathrm{~L} / \mathrm{s}$. A eficiência na retenção destes sólidos foi de $100 \%$.

O tempo de filtragem não foi mensurado, visto que o filtro do interceptor não apresentou retenção significativa da água, por ter boa permeabilidade e baixa saturação de areia.

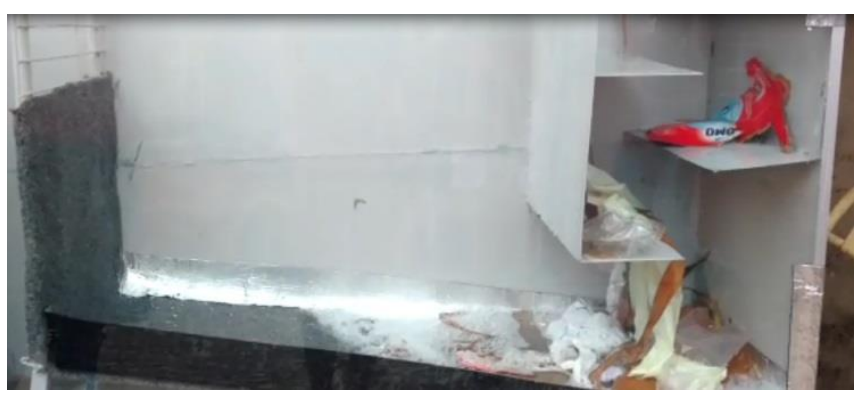

Figura 5 - Resíduos retidos no teste do Interceptor

Fonte - Arquivo pessoal, 2016.

Foram feitas cotações de preços em fábricas de produtos pré-moldados de concreto, para fabricação do protótipo, o valor sugerido pela empresa foi de $\mathrm{R} \$ 360,00$, bem próximo do valor de uma Boca de Lobo comum, $\mathrm{R} \$ 212,00$. Vale ressaltar que o valor sugerido pela empresa consultada consiste no preço de 01 unidade, e o preço para a boca de lobo comum é o preço para licitações, ou seja, para muitas unidades, de modo que se o Interceptor for produzido em grande quantidade o valor será menor que o sugerido.

\section{CONCLUSÃO}

O protótipo do interceptor de areia e outros resíduos apresentou grande eficiência, retendo praticamente toda a areia carreada, bem como todos os demais resíduos utilizados. A areia que passou pelo filtro, além da baixa granulometria, menor que $75 \mu \mathrm{m}$, teve um volume muito baixo, aproximadamente $1,75 \mathrm{~kg}$ de areia a cada 1000 litros de água passado pelo filtro, nas devidas proporções utilizadas. 


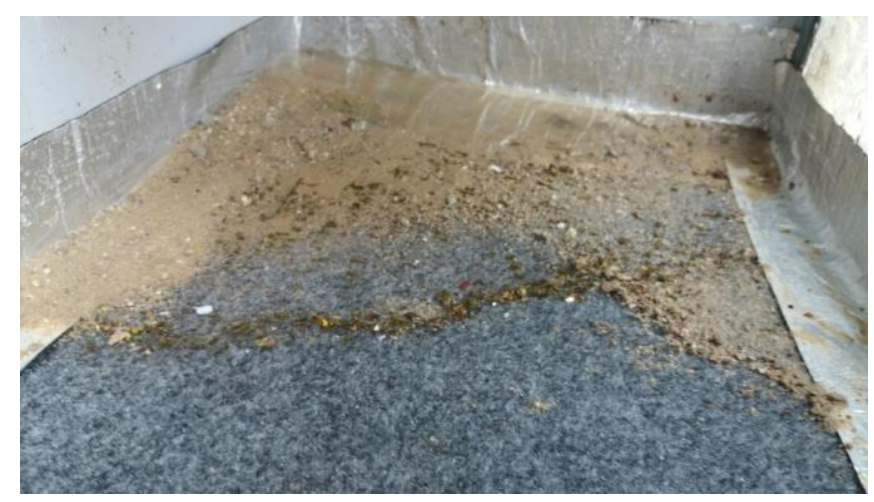

Figura 6 - Areia retida no filtro do Interceptor

Fonte - Arquivo pessoal, 2016.

Este poderá contribuir para a redução de assoreamento dos corpos hídricos, visto que a areia ficará retida no Interceptor, redução dos alagamentos ocorridos por entupimento das bocas de lobo, visto que o Interceptor terá passagem de emergência para quando houver obstrução por excesso de resíduos na câmara de retenção, e redução das obstruções das redes pluviais. Isso contribuirá para a saúde ambiental das cidades, fazendo parte do planejamento urbano. Além disso poderá minimizar um transtorno hidráulico causado pela intensa impermeabilização das cidades, acentuadas pelas precipitações pluviais, visto que os dimensionamentos das redes coletoras pluviais não têm comportado o volume de água precipitado somado aos resíduos sólidos e areia carreados.

\section{REFERÊNCIAS BIBLIOGRÁFICAS}

BRASIL. Belo Horizonte. Prefeitura Municipal de Belo Horizonte. Dispõe sobre a Limpeza Urbana Seus Serviços e Manejo de Resíduos Sólidos Urbanos no Município. Lei 10.534. 10 de Setembro 2012. Disponível em: http://www.google.com.br/url?sa=t\&rct=j\&q=\&esrc=s\&frm=1\&source=web\&cd=1\&sq $\underline{\mathrm{i}=2 \& v e d=0 a h U K E w i D 4 L X N p u L O A h W B F Z A K H a d b C 2 o Q F g g c M A A \& u r l=h t t p \% 3 A}$ \%2F\%2Fportalpbh.pbh.gov.br\%2Fpbh\%2Fecp\%2Ffiles.do\%3Fevento\%3Ddownload\% 26urlArqPlc\%3DLei_10.534_Limpeza_Urbana_Manejo_Residuos_solidos.pdf\&usg=A FQjCNF7f41Cz3arlGbRPzqVVRe6oouQlw\&bvm=bv.131286987,d.Y2I. Acesso em 27 ago. 2016.

DER - Departamento de Estradas de Rodagens. Especificação técnica, meios fios, sarjetas, sarjetões, drenagem. São Paulo, 2006 Disponível em: 
http://www.google.com.br/url?sa=t\&rct=j\&q=\&esrc=s\&frm=1\&source=web\&cd=2\&ve $\underline{\mathrm{d}=0 \text { ahUKEwigpc- }}$

I3OLOAhWHx5AKHcJuCrkQFggiMAE\&url=ftp\%3A\%2F\%2Fftp.sp.gov.br\%2Fftpder \%2Fnormas\%2FET-DE-H00-018_A.pdf\&usg=AFQjCNF61YuuFv1-iUpfJ5uYcilABCoIQ. Acesso em 27 ago. 2016.

FAUUSP - Faculdade de Arquitetura e Urbanismo, Universidade de São Paulo. Microdrenagem Urbana. AUT 0192 - Infraestrutura e Urbana e Meio Ambiente, 2015. São Paulo, 2015. Disponível em: http://www.google.com.br/url?sa=t\&rct=j\&q=\&esrc=s\&frm=1\&source=web\&cd=1\&ve d=0ahUKEwj_poiv7ZTQAhULIZAKHcjyAKsQFggbMAA\&url=http\%3A\%2F\%2Fww w.fau.usp.br\%2Fcursos\%2Fgraduacao\%2Farq_urbanismo\%2Fdisciplinas $\% 2$ Faut $0192 \%$ 2FAula_aut-0192-

microdrenagem.pdf\&usg=AFQjCNHXs4AUdBqMxfDiukWW_0QBdECZA\&bvm=bv.137904068,d.Y2I. Acesso em: 6 nov. 2016.

MORGADO, Marcelo. Estudo - Caracterização da Composição de Resíduos Removidos em Gradeamento de ETEs. São Paulo, 2014. Disponível em: http://www.google.com.br/url?sa=t\&rct=j\&q=\&esrc=s\&frm=1\&source=web\&cd=1\&ve d=0ahUKEwjx4OW9iabQAhUHgpAKHW70C54QFggiMAA\&url=http\%3A\%2F\%2F www.abes-

sp.org.br\%2Farquivos\%2Frevistahydro_complixo_eteabc_mar14.pdf\&usg=AFQjCNEi SOELY0Sn1ZKF_m7xe8Jz74uQEg\&bvm=bv.138493631,d.Y2I. Acesso em: 13 nov. 2016.

PORTALPBH - Prefeitura de Belo Horizonte. PBH Realiza Ações Preventivas Contra Enchentes Durante o Ano Inteiro. Belo Horizonte, 2016. Disponível em: http://portalpbh.pbh.gov.br/pbh/ecp/noticia.do?evento=portlet\&pAc=not\&idConteudo= 176958\&pIdPlc=\&app=salanoticias. Acesso em: 27 ago. 2016.

PORTALBH - Prefeitura de Belo Horizonte. Prefeitura Promove Limpeza, Vistorias e Obras para Prevenir Inundações. Belo Horizonte, 2013. Disponível em: http://portalpbh.pbh.gov.br/pbh/ecp/noticia.do?evento=portlet\&pAc=not\&idConteudo= 126327\&pIdPlc=\&app=salanoticias. Acesso em: 13 nov. 2016. 
TOMAZ, Plinio. Bocas de lobo. Guarulhos. São Paulo, 2012. Disponível em: http://www.google.com.br/url?sa=t\&rct=i\&q=\&esrc=s\&frm=1\&source=web\&cd=1\&ve d=0ahUKEwidxdnHhqbQAhXDIJAKHUliCVgQFggbMAA\&url=http $\% 3 \mathrm{~A} \% 2 \mathrm{~F} \% 2 \mathrm{Fw}$ ww.pliniotomaz.com.br\%2Fdownloads\%2Fbocasdelobo.pdf\&usg=AFQjCNFSmHLmu yr82S1_zRsQeIhJLCA8ow\&bvm=bv.138493631,d.Y2I. Acesso em: 13 nov. 2016.

TRATABRASIL. Instituto Trata Brasil, 2013. Saneamento - O que é saneamento. São Paulo, 2013. Disponível em: http://www.tratabrasil.org.br/o-que-e-saneamento. Acesso em 27 ago. 2016.

UFRRJ - Universidade Federal Rural do Rio de Janeiro. Mapa Mental dos Problemas das Enchentes Urbanas. Rio de Janeiro, S/D. Disponível em: http://www.ufrrj.br/institutos/it/de/acidentes/mma10.htm. Acesso em: 27 ago. 2016. 